\title{
Correction to: An effectiveness analysis of altmetrics indices for different levels of artificial intelligence publications
}

\author{
Xi Zhang ${ }^{1} \cdot$ Xianhai Wang ${ }^{1} \cdot$ Hongke Zhao ${ }^{1} \cdot$ Patricia Ordóñez de Pablos ${ }^{2}$. \\ Yongqiang $\mathrm{Sun}^{3} \cdot$ Hui Xiong ${ }^{4}$
}

Published online: 8 September 2021

(c) Akadémiai Kiadó, Budapest, Hungary 2021

\section{Correction to: Scientometrics (2019) 119:1311-1344 https://doi.org/10.1007/s11192-019-03088-x}

In the original publication of the article, the below mentioned reference was published with incorrect details. This has been corrected with this Correction.

The original article has been corrected.

\section{Reference}

Hassan, S. U., Imran, M., Gillani, U., Aljohani, N. R., Bowman, T. D., \& Didegah, F. (2017). Measuring social media activity of scientific literature: An exhaustive comparison of scopus and novel altmetrics big data. Scientometrics, 113(2), 1037-1057.

The original article can be found online at https://doi.org/10.1007/s11192-019-03088-x.

Xi Zhang

jackyzhang@tju.edu.cn

Hongke Zhao

hongke@tju.edu.cn

1 College of Management and Economics, Tianjin University, Tianjin 300072, China

2 Department of Business Administration, University of Oviedo, Oviedo, Spain

3 School of Information Management, Wuhan University, Wuhan 430072, China

4 Rutgers Business School - Newark and New Brunswick, Rutgers University, Newark, NJ, USA 